\title{
DIAGNÓSTICO PARCIAL DAS AÇÕES DESENVOLVIDAS PARA EDUCAÇÃO EM SAÚDE NO ENSINO PÚBLICO EM BOA VISTA/RORAIMA/BR
}

\author{
PARTIAL DIAGNOSIS OF DEVELOPED ACTIONS FOR HEALTH EDUCATION IN \\ PUBLIC EDUCATION IN BOA VISTA/RORAIMA/BR
}

\author{
Tania Renata Prochnow ${ }^{1}$ \\ Maria Luiza Coelho de Souza ${ }^{2}$ \\ Maria Eloisa Farias ${ }^{3}$
}

\section{Resumo}

Desde a constituição de 1988 ocorre a implantação do SUS (Sistema Único de Saúde) em todo o Brasil, com descentralização e municipalização das ações e dos recursos financeiros para o setor. O SUS é formado por uma rede serviços regionalizada, hierarquizada e descentralizada, com direção em cada esfera do governo e sob controle dos usuários por meio da participação popular nas conferências e conselhos de saúde. Este estudo realizado em Boa Vista, Roraima/Brasil, aponta um crescimento populacional local desordenado, o que não permitiu o acompanhamento adequado de diversos setores fundamentais, como o setor de saúde. Esta investigação no campo da saúde e qualidade de vida utilizou como instrumentos: entrevistas, pesquisa de campo e a avaliação dos programas de Educação em Saúde implantados nas escolas públicas locais. Ao descrever programas, projetos e ações realizadas nas escolas, sugere ações e soluções para a melhoria das atuais condições da educação em saúde no município de Boa Vista.

Palavras-chave: Educação. Saúde. Qualidade de Vida. Saúde Escolar.

\begin{abstract}
Since the 1988 Constitution, occurs the SUS (Sistema Único de Saúde) implementation in throughout Brazil, with decentralization and municipalization of actions and financial resources for this sector. The SUS is formed by a network regionalized services, hierarchical and decentralized with management in each sphere of government and under the control of users through popular participation in conferences and health councils. This study in Boa Vista, Roraima/Brazil, points a disordered local population growth, which did not allow appropriate monitoring of key sectors such as healthcare. This research in health and life quality field, used instruments as: interviews, field research and evaluation of health education programs deployed in local public schools. Describing programs, projects and actions carried out in schools, suggests actions and solutions to improve the current conditions of health education in the city of Boa Vista.
\end{abstract}

Keywords: Education. Health. Life Quality. School Health.

\footnotetext{
${ }^{1}$ A autora é professora pesquisadora do Programa de Pós Graduação em Ensino de Ciências e Matemática PPGECIM, da Universidade Luterana do Brasil, bem como dos cursos de graduação em Química Industrial, Licenciatura em Química e Engenharia Ambiental. E-mail: taniapro@gmail.com

${ }^{2}$ A autora é Mestranda do Programa de Pós-Graduação em Ensino de Ciências e Matemática - PPGECIM, da Universidade Luterana do Brasil. E-mail: luiza.coelho11@gmail.com

${ }^{3}$ Professora pesquisadora do Programa de Pós Graduação em Ensino de Ciências e Matemática - PPGECIM, da Universidade Luterana do Brasil. E-mail: mariefs10@yahoo.com.br
} 


\section{INTRODUÇÃO}

Dentro de sua especificidade histórica e econômica, o estado de Roraima vem sofrendo um crescimento populacional significativo em relação aos demais estados, desde a década de 70. Este crescimento populacional desordenado provocou um impacto relevante sobre a qualidade de vida da população local, uma vez que as políticas públicas estaduais e municipais não conseguiram atender a demanda, caracterizando um quadro nada sustentável; logo, se percebeu a necessidade de intervenção na saúde, organizando a mediação do conhecimento efetivo através dos professores. Pereira (2009), discorrendo sobre a educação, ressalta sua competência transformadora na construção de cidadania levando à mudanças positivas de atitudes.

Desde a constituição cidadã de 1988, é defendida a municipalização e a descentralização das ações e de recursos financeiros para o setor da saúde. A partir desta, em 19 de setembro de 1990, foi criado o Sistema Único de Saúde (SUS), pela lei nº 8.080 - a Lei Orgânica da Saúde. Esta lei expressa o princípio constitucional como direito de todos e dever do estado e enfatiza a descentralização dos serviços para os municípios. (REIS et al, s/d).

Arretche e Marques (2002) discorrem que o Sistema Brasileiro de Proteção Social sofreu transformações diferenciadas, sob a influência de diferentes políticas e também entre os diferentes estados brasileiros, interferindo no processo de descentralização e no de municipalização das políticas sociais.

Dentro desse processo de mudanças, do período de 1996 em diante, o setor municipal de saúde de Boa Vista/RR vem se adequando quantitativa e qualitativamente no atendimento à população, havendo implantação do programa regional de educação ambiental, de educação em saúde, e de ações e discussões para um desenvolvimento sustentável. Apesar destas adequações, os entraves burocráticos, administrativos e políticos apresentavam um quadro deficitário.

Conforme Cecílio et al (2007, p.202)

[...] esse processo de descentralização, em curso, tem propiciado um campo fértil à experimentação prática e instrumental em planejamento e organização de serviços de saúde. Os gestores municipais vêm se constituindo como importantes atores sociais no cenário politico institucional do SUS.

Paim e Teixeira (2007) apontam para a necessidade de qualificação de gestores e de profissionais comprometidos que levem a consolidação do processo. Temas de saúde estão 
presentes no cotidiano da população em geral e se fazem presentes também nas salas de aulas, proporcionando oportunidade para a realização de práticas pedagógicas contextualizadas e interdisciplinares (BRASIL, 1998). A forma de ação da então denominada Escola Promotora de Saúde é a de transformar a escola em um núcleo promotor de saúde, integrando a escola e a sociedade, partindo da premissa de agir além da sala de aula, em parceria com outras entidades. Nela a educação acontece pela junção de escola, família e comunidade e não apenas por ação do currículo; assim os educadores atuam com os alunos e com a comunidade, admitindo seu papel na melhoria da sociedade (GAVIDIA, 2009). Isto porque a escola é a instituição que se dedica a construção da cidadania onde os valores morais, sociais, culturais e pessoais são desenvolvidos e fixados. (BRASIL, 2002).

A Educação em Saúde (ES), por ser uma prática transversal, é uma importante ferramenta no processo de conscientização individual e coletiva de responsabilidade e direitos à saúde, representando um dispositivo fundamental para a formulação de políticas de saúde e para as ações que relacionam diretamente os serviços com os usuários. (BRASIL, 2007).

O Ministério da Saúde, através da proposta de Educação Plena em Saúde (EPS), instituída pela Política Nacional de Educação Permanente em Saúde (PNEPS) a partir de 2004, prevê transformar e qualificar as ações e os serviços, os processos formativos e, ainda, as práticas pedagógicas e de saúde, baseadas em uma educação com aprendizagem significativa. (BRASIL, 2005).

De acordo com o projeto de promoção da saúde (BRASIL, 2009), da Secretaria de Políticas de Saúde do Ministério da Saúde, é necessário sistematizar as propostas de intervenções em todos os setores educacionais, por ser apoio importante na realização destas ações, fortalecendo assim a capacidade para a tomada de decisões relacionadas à saúde e bem estar. Isto é reforçado por Gomes (2009), que afirma que uma escola promotora de saúde é caracterizada como uma instituição que procura constantemente um estilo de vida, de aprendizagem e de trabalho propício ao desenvolvimento da saúde.

Portanto, os profissionais que atuam em EPS precisam passar por um processo de aprendizagem que envolva conhecimentos teóricos, de prática profissional, de troca de experiências, relacionamento e conhecimento técnico dentro da equipe, o que implica em pensar políticas e ofertas de formação e qualificação (MACEDO et al., 2014). Ainda segundo estes autores:

[...] os processos de formação dos profissionais são pensados levando-se em consideração as necessidades identificadas na prática dos serviços e a sua implementação, realizada por meio de metodologias de ensino-aprendizagem que 
incluem tanto a problematização dos processos e vivências do cotidiano como a produção científica (reflexão teórica) sobre a prática. (MACEDO et al., 2014, p $383)$.

A capital do Estado de Roraima, Boa Vista, vem se adequando no que diz respeito ao atendimento populacional, realizando implantação de diversos programas de saúde, dos quais, alguns foram direcionados à rede estadual de ensino para atender aos alunos da educação básica, a saber: Programa Odontológico, Programa Oftalmológico, e Programa de Primeiros Socorros (SESAU, 2011). É necessário, entretanto, que os programas de saúde criados na rede estadual de ensino não apenas atendam aos alunos da educação básica de modo isolado, mas que sejam abordados em todas as disciplinas como temas transversais, conforme o estabelecido pelos Parâmetros Curriculares Nacionais-PCN (BRASIL, 1998). Percebe-se que os temas de saúde têm sido trabalhados apenas nas disciplinas de Ciências e, normalmente, ficam restritas aos conteúdos disponíveis no livro didático.

Dada a grande relevância para a saúde e para a educação, este trabalho foca a educação em saúde a fim de alcançar mudanças expressivas não somente nos alunos, mas em toda a comunidade escolar, para hábitos mais saudáveis. A Organização Mundial de SaúdeOMS adotou, em 1948, o conceito de saúde como um completo estado de bem estar físico, mental e social e não apenas a ausência de doença (BRASIL, 1998). Nas Diretrizes Curriculares Nacionais encontramos que "O conceito de qualidade na escola, numa perspectiva ampla e basilar, remete a uma determinada ideia de qualidade de vida na sociedade e no planeta Terra". (BRASIL, 1998, p.21).

\section{BOA VISTA/RR E A EDUCAÇÃO EM SAÚDE}

O Estado de Roraima está localizado no extremo setentrional do país, sendo cortado ao sul pela linha do Equador, com sua maior área localizada no hemisfério norte. Ao todo a área geográfica é de $224.298 .980 \mathrm{~km}^{2}$. As fronteiras internacionais delimitam-se com a República Bolivariana da Venezuela (norte e oeste), por $958 \mathrm{~km}$ e com a República Cooperativista da Guiana (norte e leste), por $964 \mathrm{~km}$. Ao sul e oeste faz divisa com o estado do Amazonas e a Leste com Estado do Pará. (IBGE, 2011).

A cidade de Boa Vista está localizada no centro-leste do Estado de Roraima, à margem direita do Rio Branco. A população da capital, segundo IBGE (2011), era de 284.250 habitantes e sua área é de $5.687 \mathrm{Km}^{2}$, correspondendo a 2,54\% do Território do Estado de 
Roraima. A temperatura média anual é de $27,4^{\circ} \mathrm{C}$, variando de $20^{\circ} \mathrm{C}$ a $38^{\circ} \mathrm{C}$. No município de Boa Vista concentra-se $70 \%$ da população do estado. Assim, a municipalidade enfrenta os desafios de criar uma infraestrutura que realmente melhore o atendimento ao ensino e a assistência de saúde da população, como habitação, saneamento básico, emprego e exploração racional dos recursos naturais, de maneira a atender o desenvolvimento sustentável que precisamos e queremos. (IBGE, 2011).

O crescimento populacional de Boa Vista tem ocorrido de forma dinâmica e desordenada, o que não permite o acompanhamento adequado de setores fundamentais como saúde, educação e segurança, provocando impacto relevante sobre a qualidade de vida da população local, uma vez que as políticas públicas estaduais e municipais não conseguem atender esta demanda.

Em relação à Promoção da Saúde (PS), Buss e Carvalho (2009) comentam:

\footnotetext{
'Cidades/municípios/comunidades saudáveis' é estratégia de implementação da PS reconhecida em todo o mundo62-64. Apesar de tal relevância, apenas iniciativas limitadas de cidades/comunidades saudáveis estão em curso no Brasil sem, contudo, organizarem-se nacionalmente. (BUSS; CARVALHO, 2009, p. 2310).
}

Há interesse acadêmico para análise dessa problemática social e pública na cidade de Boa Vista/RR. Portanto, este trabalho trata de escolas e programas de educação em saúde ali implantados, na capital de Roraima, Boa Vista.

Segundo Silva et al (2014) comissões de integração ensino-serviço regionais são o primeiro fórum de discussões e de construções coletivas em conformidade com as necessidades e as demandas de educação permanente em saúde. Preconiza-se que coordenadorias regionais sejam detentoras de conhecimentos sobre as questões atinentes à saúde, a recursos materiais, equipamentos e recursos humanos nos seus respectivos territórios. (SILVA et al., 2014).

Este trabalho analisa as ações e projetos voltados para a Educação em Saúde, desenvolvidos na rede estadual de ensino público, suas contribuições na melhoria da qualidade de vida do educando, sua vinculação com conteúdos de Ciências do ensino fundamental e investiga a percepção dos gestores, professores e alunos, em relação aos programas desenvolvidos na escola e a realidade vivenciada.

Em relação aos gestores, Cecilio et al. (2007) observaram uma grande rotatividade na gestão municipal na saúde, além do despreparo dos mesmos e uma imensa sobrecarga com tarefas impostas pelos "níveis superiores" do sistema. 
A escola, por ser um espaço onde muitos circulam - aprendizes e trabalhadores - se constitui num ambiente de grande repercussão para projetos e programas de Educação em Saúde, alcançando os alunos nas principais fases de suas vidas (BRASIL, 2002). Muito do que se entende a respeito de saúde está relacionado com o que se aprende na escola e na sala de aula. Para Silva et al. (2014) é aí que ocorre uma imersão em um espaço diferenciado, potencializando e aproximando o saber do fazer, levando à ações coletivas e efetivando a integração docente-assistencial.

Na educação em saúde os saberes científicos produzidos nessa área atingem a vida cotidiana da população, possibilitando a melhoria da saúde e da qualidade de vida, sendo a prática em saúde que mais se aproxima do pensar e agir das pessoas, permitindo a construção de saberes por meio da interface entre usuários e profissionais, fundamentada nos aspectos emancipatório e político da constituição humana, não somente voltada para determinantes biológicos da saúde, mas incorporadora da formação para a cidadania. (ALVES, 2005; VASCONCELOS, et al, 2009).

Neste sentido, as questões referentes à saúde eram tratadas por varias disciplinas, até a Lei $n^{\circ} 5.692 / 71$ acrescentar oficialmente a temática de saúde ao currículo escolar brasileiro, como "Programa de Saúde". Com base nesta lei, Programas de Saúde deveriam ser abordados não como disciplina, mas por meio de atividades que favorecessem a constituição de comportamentos e a obtenção de conhecimentos e valores capazes de estimular comportamentos que permitissem aos alunos a tomada de decisões corretas no que se refere à saúde. (BRASIL, 1998).

É preciso educar para a saúde levando em conta todos os aspectos envolvidos na formação de hábitos e atitudes que acontecem no dia-a-dia da escola. Por esta razão, a educação para a saúde será tratada como tema transversal, permeando todas as áreas que compõe o currículo escolar. (BRASIL, 1998, p. 245).

Na Educação em Saúde o professor deve atuar como mediador e motivador, como aquele que apresenta os problemas atuais, auxilia na busca de informações e materiais complementares, provoca e gerencia as discursões com base em seu trabalho escolar (BRASIL, 1998). O tema transversal Saúde, aborda as relações entre os problemas de saúde e fatores econômicos, políticos, sociais e históricos, possibilitando a construção da cidadania em função da relação que cria entre o indivíduo e seu ambiente. (FERNANDES; BACKES, 2010). 
É importante ressaltar que a maioria dos temas de Educação em Saúde abordados na escola é apresentada nas aulas de Ciências ou de Biologia como se a temática só pudesse ser abordada nessas disciplinas, mesmo sendo relacionada ao tema transversal Saúde proposto nos PCN como um tema para ser trabalhado em todas as disciplinas do currículo escolar (GOMES; ZANCUL, 2010). Os quatro eixos temáticos existentes para serem trabalhados na disciplina Ciências Naturais são: Terra e Universo, Vida e Ambiente, Ser Humano e Saúde, Tecnologia e Sociedade (BRASIL, 1998). O eixo escolhido para ser abordado neste trabalho é "Ser Humano e Saúde”, uma vez que se identifica com a pesquisa em questão.

Assim, pode-se também citar um dos vários objetivos que os Parâmetros Curriculares Nacionais estabelecem para o Ensino Fundamental, pois também apresenta grande relevância neste trabalho:

[...] que os alunos sejam capazes de conhecer o próprio corpo e dele cuidar, valorizando e adotando hábitos saudáveis como um dos aspectos básicos da qualidade de vida e agindo com responsabilidade em relação à sua saúde e à saúde coletiva. (BRASIL, 1998, p.12).

O tema transversal saúde, ao abordar as relações entre os problemas de saúde e fatores econômicos, políticos, sociais e históricos, acarreta discussões sobre responsabilidades humanas voltadas ao bem estar comum e condições e objetivos da saúde que, para serem trabalhados, necessitam da cooperação da área de Ciências, mas nela não se esgotam. (BRASIL, 1998).

Moutinho et al (2014) ponderam que é relevante refletir sobre a prática educativa em saúde como produtora de cuidado e transformadora de contextos sociais e de vida. É também preciso problematizar as barreiras que dificultam sua efetivação, seja no interior do trabalho da equipe, seja nos desencontros com a própria população. (MOUTINHO et al., 2014).

Os Programas de Saúde na Escola (PSE), elaborados pelo Ministério da Educação (MEC) e o Ministério da Saúde (MS) em 2007, são propostas que possibilitam e garantem uma aprendizagem efetiva e transformadora de atitudes e hábitos para uma vida saudável. Encontramos no Portal do MEC, nas Diretrizes Curriculares Nacionais, que ao educar para saúde de forma contextualizada e sistemática, toda a equipe contribui de forma decisiva na formação de cidadãos capazes de atuar em favor da melhoria dos níveis de saúde pessoal e da comunidade escolar (BRASIL, 2013). O Ministério da Saúde (BRASIL, 2011, p. 15) instituiu em sua cartilha as diretrizes dos PSE: 
I - promover a saúde e a cultura da paz, reforçando a prevenção de agravos à saúde, bem como fortalecer a relação entre as redes públicas de saúde e de educação;

II - articular as ações do Sistema Único de Saúde - SUS às ações das redes de Educação Básica pública, de forma a ampliar o alcance e o impacto de suas ações relativas aos estudantes e suas famílias, otimizando a utilização dos espaços, equipamentos e recursos disponíveis;

III - contribuir para a constituição de condições para a formação integral de educandos;

IV - contribuir para a construção de sistema de atenção social, com foco na promoção da cidadania e nos direitos humanos;

$\mathrm{V}$ - fortalecer o enfrentamento das vulnerabilidades, no campo da saúde, que possam comprometer o pleno desenvolvimento escolar;

VI - promover a comunicação entre escolas e unidades de saúde, assegurando a troca de informações sobre as condições de saúde dos estudantes; e

VII - fortalecer a participação comunitária nas políticas de Educação Básica e saúde, nos três níveis de governo.

O MS, além de incentivo financeiro com repasse de fundos para o município, ficará responsável pela publicação de almanaques para distribuição aos alunos das escolas atendidas pelo PSE.

\section{METODOLOGIA DESENVOLVIDA}

Este trabalho foi desenvolvido no ano de 2014, durante a realização de mestrado em Programa de Pós-Graduação em Ensino de Ciências (PPGECIM), em universidade particular localizada no Rio Grande do Sul, Brasil.

Neste trabalho se analisa como as ações voltadas para a Educação em Saúde, desenvolvidas na rede estadual de ensino em Roraima, podem contribuir para a qualidade de vida do educando, bem como a vinculação destas com os conteúdos de Ciências do Ensino Fundamental. A analise realizada também contemplou as concepções de gestores e professores sobre os Programas de Saúde desenvolvidos na escola em relação à realidade vivenciada por eles. Junto aos alunos, analisou como estas ações podem contribuir para a melhoria da sua qualidade de vida.

Na capital de Roraima, Boa Vista/RR, existem 61 Escolas Públicas Estaduais de Ensino Médio e Fundamental, destas, 45 oferecem o Ensino de $6^{\circ}$ ao $9^{\circ}$ ano, e destas apenas três têm trabalhos sistematizados sobre saúde voltada aos alunos, sendo este o critério de escolha como objeto de investigação que expressamos a seguir.

A Escola $n^{o} 1$ está situada em um bairro de classe social média baixa, próximo ao centro da capital; a maioria dos alunos são moradores do próprio bairro, nessa escola ocorre um trabalho pouco mais direcionado e sistematizado: a mesma desenvolve vários projetos e 
ações de educação e saúde, em interação com os profissionais de saúde existentes na escola, cirurgião dentista e auxiliar de saúde.

As Escolas $n^{o} 2$ e $n^{o} 3$ se localizam em bairros mais afastados do centro da capital, periferia da cidade, e se enquadram em classes sociais menos favorecidas; o corpo discente é formado por alunos que residem no próprio bairro e oriundos de outras regiões da cidade. $\mathrm{O}$ trabalho nessas escolas é mais pontual com algumas ações durante o ano; nessas duas escolas também existem profissionais de saúde, cirurgião dentista e auxiliar de saúde.

Para a análise, foram realizadas entrevistas semiestruturadas com membros da equipe gestora de cada unidade escolar analisada, ao todo três sujeitos, a fim de identificar as ações formais e informais efetivadas na escola, no que diz respeito aos programas de saúde; entrevistas semiestruturadas foram realizadas também com professores, um total de nove sujeitos, para verificar como os mesmos se integram aos programas de saúde existentes em sua escola e o grau de importância que lhes conferem; também foram aplicados questionários a 180 alunos do ensino fundamental, com perguntas abertas e fechadas relativas aos programas e projetos de saúde existentes na escola. A intenção foi investigar como a escola aborda tais temáticas, tanto em nível de currículo formal, quanto em ações junto à comunidade escolar, além de investigar a realidade vivenciada.

Foram analisados três programas de saúde desenvolvidos na rede escolar. Programa Saúde Bucal - que atende aos alunos matriculados na rede estadual de ensino, focado em ações curativas e prevenção a carie através de procedimentos odontológicos e palestras educativas. Este assunto se insere nos temas Higiene e Saúde e Ambiente e Saúde, abordados nos conteúdos de ensino fundamental. O Programa Olho Vivo, com consultas oftalmológicas e confecção de óculos; contempla o tema Visão (Luz e cor; luz, sombra e espelhos; luz e olho humano; retina e projeção da imagem; papel da retina no cérebro; a pupila; o cristalino; movimento dos olhos; correção visual) abordado nas escolas. Já o Programa Saúde e Prevenção na Escola, aborda a promoção da saúde sexual e da saúde reprodutiva, visando redução da vulnerabilidade dos adolescentes e jovens às DST e AIDS, bem como a violência sexual e a gravidez não planejada. Também inclui outras abordagens em aula através da temática Ser Humano e Saúde (Partes do corpo, Órgãos dos sentidos e suas respectivas funções, DST/ AIDS).

Os programas de saúde são desenvolvidos nas escolas por profissionais da área da saúde, devendo ser abordados em sala de aula, também pelos professores. 


\section{RESULTADOS E DISCUSSÃO}

A seguir, são apresentados alguns dos resultados parciais obtidos neste trabalho. Com base na escala de Likert, foi solicitado aos professores e gestores entrevistados um valor quantitativo para os questionamentos, considerando em ordem crescente de importância: 1(muito pouco), 2 (pouco), 3 (razoável), 4 (bom), 5 (ótimo) e NO (não opinaram).

Questionados sobre o tópico Discussões sobre o tema saúde em sala de aula são motivação para o crescimento da capacidade reflexiva e crítica dos alunos, dez indicaram bom e dois indicaram ótimo. Pode-se observar nesta análise que, apesar de ser proposto no currículo e no Projeto Político Pedagógico da escola - PPP, os pesquisados ainda não tem o entendimento total do grau de importância das discussões da temática saúde na escola, não expressando a devida importância que este tema deve ter.

Segundo Gomes (2009), uma escola promotora de saúde pode ser caracterizada como uma escola que procura constantemente um estilo de vida, de aprendizagem e de trabalho propício ao desenvolvimento da saúde, onde a mudança mais importante a implementar nesta dimensão é a de que tanto alunos como professores sejam capazes de relacionar, cada vez mais e mais facilmente, os conteúdos das disciplinas à vida.

No tópico Orientações sobre saúde discutidas na escola favorecem o diálogo com a família, dez entrevistados responderam: ótimo e dois responderam: bom, enfatizando a importância de se tratar destes temas, não apenas para a educação formal, mas também para levar os assuntos à comunidade.

Souza et al (2012) indicam que, nesse espaço que contempla unidades escolares e os sujeitos de sua comunidade, as equipes de saúde podem construir e fortalecer a articulação com a população escolar e incentivar que o aluno transponha os muros da instituição, ampliando e enriquecendo a sua visão sobre a realidade sociopolítica local por meio da Unidade de Saúde da Família em que está inserido. Sendo a família a unidade primária de cuidado em saúde, é a entidade que transmite os valores éticos e humanitários regentes de seus membros, na qual se aprofundam laços de solidariedade e respeito. Em relação à este tema, encontramos nos PCN Saúde que:

A realização de estudos de reconhecimento da região em que se insere a escola e das concepções e necessidades de saúde que lhe são características é um instrumento essencial para montar e desenvolver o projeto educativo. A fluidez das relações entre a escola, a família e demais instituições, grupos organizados e entidades cujas ações repercutem sobre a saúde, é condição para contextualizar a educação para a Saúde e, ao mesmo tempo, um componente amplificador da ação educativa. (BRASIL, 1997, p 274). 
No tópico: $O$ conhecimento sobre os programas de saúde realizados na escola inclui a necessidade dos envolvidos estarem atualizados sobre os mesmos, um respondeu: razoável, dois responderam: bom e nove responderam: ótimo. Como observamos neste quesito a grande maioria dos pesquisados acredita que os envolvidos nos programas de saúde devam estar atualizados sobre o seu desenvolvimento, para melhor administrá-lo e divulgar os resultados das metas alcançadas, proporcionando uma democratização das ações em saúde na escola.

Os PCN fundamentam a concepção de saúde no exercício da cidadania, argumentando que é preciso capacitar os sujeitos a se apropriarem de conceitos, fatos, princípios, tomar decisões, realizar ações e gerar atitudes saudáveis na realidade em que os mesmos estão inseridos (BRASIL, 1997). Segundo Macedo et al. (2014, p.383) os profissionais que atuam na educação em saúde "[...] são considerados atores reflexivos com capacidade de propor soluções e inovações na assistência e gestão da saúde”. Assim sendo:

[...] os processos de formação dos profissionais devem levar em consideração as necessidades identificadas na prática dos serviços e a sua implementação, realizada por meio de metodologias de ensino-aprendizagem que incluem tanto a problematização dos processos e vivências do cotidiano como a produção científica (reflexão teórica) sobre a prática. (MACEDO et al., 2014, p. 383).

Conforme o Gestor da Escola 01: O programa de saúde na escola tem sido de grande importância para toda comunidade escolar; o mesmo vem disseminando a importância da saúde do aluno, enfatizando a boa alimentação, o bem estar com o corpo inteiro, principalmente com os dentes, pois estes são o cartão postal do rosto.

Sayão (1997, p.112), define os programas de saúde como:

Processo de intervenção planejado, intencional e sistemático, que inclui o esclarecimento de dúvidas, o questionamento das posições estanques e a ressignificação das informações e valores incorporados e vivenciados no decorrer da vida de cada criança ou jovem.

Santos et al. (2011) argumentam que, apesar de sua complexidade, a ES é viável e possível, devendo os profissionais de saúde promove-la para mobilizar e direcionar o cidadão para uma sociedade mais fraterna e comprometida na promoção da vida, onde os mesmos sejam receptivos e coparticipantes desse processo, envolvendo a educação e a saúde.

$\mathrm{Na}$ pesquisa, o questionário aplicado aos alunos revela uma percepção bastante diferenciada da evidenciada pelos professores e gestores (Tabela 1). Dos 180 alunos entrevistados, em torno de um terço preferiu não manifestar sua opinião (NO), porém mais que um terço avaliou bem os programas, apontando as alternativas 4 e 5 (bom e ótimo) em 
suas avaliações, principalmente em relação às afirmativas 1.1, 1.4 e 1.6, enfatizando a importância de se discutir o tema de saúde em sala de aula, aliadas às ações preventivas realizadas pelos programas de saúde na escola, para a melhoria da qualidade de vida. Foi igualmente notável o entendimento que estes alunos expressaram em relação à obrigatoriedade governamental na disponibilização dos programas de saúde para a população. Em relação às demais alternativas, mais de um terço manifestou percepção favorável à atuação da escola e dos serviços de saúde em relação à melhoria da qualidade de vida, não apenas do educando, mas também de sua família e da comunidade.

Tabela 1- Percepções dos alunos quanto às ações desenvolvidas com a contribuição para a qualidade de saúde/ensino

\begin{tabular}{|c|c|c|c|c|c|c|c|c|}
\hline & \multirow{2}{*}{ AFIRMATIVAS } & \multicolumn{6}{|c|}{ Alternativas de Avaliação } & \multirow{2}{*}{$\begin{array}{c}\text { Total dos } \\
\text { pesquisados }\end{array}$} \\
\hline & & 1 & 2 & 3 & 4 & 5 & NO & \\
\hline \multirow{6}{*}{$\begin{array}{l}\text { Em relação } \\
\text { aos } \\
\text { Programas } \\
\text { de Saúde- PS } \\
\text { analisados . }\end{array}$} & $\begin{array}{l}\text { 1.1 O tema saúde, quando } \\
\text { discutido em sala de aula, } \\
\text { favorece as condições para a } \\
\text { melhoria da qualidade de } \\
\text { vida. }\end{array}$ & 6 & 1 & 33 & 38 & 52 & 50 & 180 \\
\hline & $\begin{array}{l}1.2 \text { O desenvolvimento de } \\
\text { ações educativas na escola é o } \\
\text { meio para integrar a família e } \\
\text { a comunidade. }\end{array}$ & 11 & 18 & 40 & 37 & 23 & 51 & 180 \\
\hline & $\begin{array}{l}\text { 1.3 Os programas de saúde } \\
\text { existentes nas escolas, } \\
\text { atendem satisfatoriamente. }\end{array}$ & 14 & 16 & 37 & 33 & 29 & 51 & 180 \\
\hline & $\begin{array}{l}\text { l.4 As ações preventivas sobre } \\
\text { saúde bucal, favoreceram a } \\
\text { qualidade de vida dos alunos. }\end{array}$ & 7 & 6 & 23 & 32 & 55 & 57 & 180 \\
\hline & $\begin{array}{l}1.5 \text { Os serviços de saúde } \\
\text { bucal oferecidos na escola } \\
\text { atendem a demanda e } \\
\text { propiciam melhores condições } \\
\text { de vida aos beneficiados. }\end{array}$ & 8 & 14 & 37 & 33 & 34 & 54 & 180 \\
\hline & $\begin{array}{l}\text { 1.6 Os Programas de Saúde } \\
\text { disponibilizados pelo Governo } \\
\text { fazem parte de suas } \\
\text { obrigações para com a } \\
\text { população. }\end{array}$ & 12 & 13 & 20 & 29 & 55 & 51 & 180 \\
\hline
\end{tabular}

Fonte: a pesquisa 
Porém uma parcela importante, quase outro terço dos entrevistados, não fez uma boa avaliação quanto às ações desenvolvidas. Esta percepção, manifestada através do ICD, foi mais forte principalmente em relação às ações desenvolvidas pela escola como meio de integrar a família e a comunidade, o atendimento realizado pelos programas de saúde na escola e o serviço de saúde bucal oferecido, onde mais de um terço dos entrevistados manifestou percepções desfavoráveis.

Silva et al. (2014) observam a necessidade de mais estudos sobre condições de saúde e qualidade de vida de adolescentes no contexto escolar onde estão inseridos, objetivando analisar fatores de risco, planejamento e práticas avaliativas para esta população. Observam ainda que:

Incluir a família no plano de cuidados tem sido apontado como uma das maiores possibilidades de intervenção na área da saúde, corroborando para um maior entendimento dos processos referenciais que traduzem a relação familiar e sua correlação com o processo saúde-doença. (SILVA et al, 2014, p. 29).

Ferreira et al (2014) ponderam que "educar é mais do que apenas informar; é pensar a partir da reunião de histórias de vida do cidadão, em que haja direcionamento para a reflexão das necessidades, ou não, de mudanças na trajetória dessas vidas”. A educação objetiva oportunizar reflexões e ações que possibilitem um aprendizado consciente, sem, no entanto, intencionar um controle da vida do cidadão. A educação em saúde deve propiciar encontros entre profissionais e usuários do serviço de saúde e fomentar o diálogo e a troca de experiências (FERREIRA et al, 2014). Ainda, segundo estes autores:

A priori, a educação em saúde é uma construção em movimento; por esta razão torna-se fundamental trabalhar situações conforme a realidade das pessoas, valorizando aspectos culturais, as relações de gênero e os diferentes níveis socioeconômicos e políticos. (FERREIRA et al, 2014, p 372).

\section{CONCLUSÕES}

O estudo valida que os Programas de Saúde auxiliam os alunos de maneira positiva, pois a escola além de promover o desenvolvimento social, intelectual, provoca uma discussão, uma reflexão sobre a formação do aluno cidadão. É necessário que os envolvidos nestes programas estejam atualizados e comprometidos com os mesmos.

Informações como o funcionamento do corpo humano, doenças e higiene não têm sido suficientes para a transformação de hábitos e mudanças de comportamento. Uma abordagem mais significativa da saúde, atrelada à qualidade de vida, possibilita esclarecer os fatores 
sociais envolvidos na promoção da saúde, gerando percepção da necessidade de conscientização quanto ao direito à melhoria na qualidade de vida.

Estas práticas educativas são de extrema importância, pois facilitam as trocas de experiências, a construção de conhecimentos e de aprendizagens entre professores, profissionais da área da saúde e a comunidade escolar; porém este trabalho evidenciou a necessidade de uma formação continuada da equipe de profissionais envolvidos, tanto os da área da saúde como os da educação que, ao longo do tempo, permita o aprimoramento de sua atuação nos Programas de Saúde na escola. Como consequência, haverá maior abrangência no processo de promoção de saúde escolar, contribuindo na formação global e holística, fortalecendo a relação escola-família, a cooperação entre diferentes serviços e o exercício pleno da cidadania.

\section{REFERÊNCIAS}

ALVES, V. S. Um modelo de educação em saúde para o Programa Saúde da Família: pela integralidade da atenção e reorientação do modelo assistencial. Interface: Comunicação, Saúde, Educação, Botucatu, v. 9, n. 16, p. 39-52, set. 2004/fev. 2005.

ARRETCHE, M.; MARQUES, E. Municipalização da Saúde no Brasil: diferenças regionais, poder do voto e estratégias de governo. Ciência \& Saúde Coletiva, Rio de Janeiro, v.7, n.3, p.455-479, jul.-set. 2002.

BRASIL - PCN - Temas Transversais - Saúde. Ministério da Educação - Secretaria de Educação Básica, Brasília, 1997. Disponível em:

<https://www.google.com.br/?gws_rd=ssl\#q=pcn+temas+transversais+sa\%C3\%BAde>

. Secretaria de Educação Fundamental. Parâmetros Curriculares Nacionais: Ciências Naturais. Secretaria de Educação Fundamental. Brasília: MEC/SEF, 1998.

. Ministério da Saúde. Política Nacional de Promoção da Saúde. Brasília - 2002.

. Ministério da Saúde. Secretaria de Gestão do Trabalho e da Educação na Saúde.

Departamento de Gestão da Educação em Saúde. A educação permanente entra na roda: polos de educação permanente em saúde - conceitos e caminhos a percorrer. Brasília:

Ministério da Saúde, 2005. Disponível em:

<http://bvsms.saude.gov.br/bvs/publicacoes/educacao_permanente_entra_na_roda.pdf>

- Ministério da Saúde. Secretaria de Gestão Estratégica e Participativa. Departamento de Apoio à Gestão Participativa. Caderno de Educação Popular e Saúde, Brasília, DF: Ministério da Saúde, 2007. 
BRASIL. Ministério da Saúde. Secretaria de Atenção à Saúde. Departamento de Atenção Básica. Saúde na escola. Brasília, DF: Ministério da Saúde, 2009. 96 p.

. Ministério da Saúde. Secretaria de Atenção à Saúde Departamento de Atenção Básica. Passo a passo PSE programa saúde na escola - tecendo caminhos da instersetorialidade. Brasília, 2011.

. Ministério da Educação. Secretaria de Educação Básica. Secretaria de Educação Continuada, Alfabetização, Diversidade e Inclusão. Conselho Nacional da Educação. Diretrizes Curriculares Nacionais Gerais da Educação Básica. Diretoria de Currículos e Educação Integral. Brasília: MEC, SEB, DICEI, 2013.

BUSS, P.M.; CARVALHO, A. I. Desenvolvimento da promoção da saúde no Brasil nos últimos vinte anos (1988-2008). Ciênc. Saúde Coletiva, Rio de Janeiro, v.14, nº.6, Dec., 2009.

CECILIO, L. C. O; ANDREAZZA, R.; SOUZA, A. L. M.; MERCADANTE, C. E. B.; VEJA, C.; LACAZ, F. A. C.; BESTETTI, L. M. A.; LIMA, M. R.; PINTO, N. R. S.; SPEDO, S. M.; SATO, W. N. S. O gestor municipal na atual etapa de implantação do SUS: características e desafios. RECIIS - R. Eletr. de Com. Inf. Inov. Saúde, Rio de Janeiro, v.1, n.2, p.200-207, jul.-dez., 2007.

FERNANDES, M. C. P.; BACKES, V. M. S. - Educação em saúde: perspectivas de uma equipe da Estratégia Saúde da Família sob a óptica de Paulo Freire. Revista Brasileira de Enfermagem, Brasília, v. 63, n. 4, p. 567-573, jul./ago. 2010.

FERREIRA, V. F., ROCHA, G. O. R., LOPES, M. M. B., SANTOS, M. S., MIRANDA, S. A. - Educação em Saúde e cidadania: revisão integrativa. Trab. Educ. Saúde, Rio de Janeiro, v. 12 n. 2, p. 363-378, maio/ago. 2014

GAVIDIA, V. El professorado ante la educación y promoción de lasaluden la escuela. In: Didàctica de lês Ciències Experimentals i Socials. Universitat de València, n. 23, 2009.

GOMES, J. P. As Escolas Promotoras de Saúde: uma via para promover a saúde e a educação para a saúde da comunidade escolar. Educação, Porto Alegre, v. 32, n. 1, p. 84-91, jan./abr. 2009

GOMES, P. H. M.; ZANCUL, M. S. Educação em Saúde nos livros didáticos de ciências para o ensino fundamental. Revista da SBEnBio, n. 3, out., 2010.

IBGE. Estados. Roraima. Disponível em: <http://http://www.cidades.com.br/estado/roraima/rr. html>. Acesso em: 22 out. 2011.

MACÊDO, N. B., ALBUQUERQUE, P. C., MEDEIROS, K. R. O desafio da implementação da educação permanente na gestão da educação na saúde. Trab. Educ. Saúde, Rio de Janeiro, v. 12 n. 2, p. 379-401,maio/ago. 2014

MOUTINHO, C. B.; ALMEIDA, E. R.; LEITE, M. T. S.; VIEIRA, M.A. Dificuldades, desafios e superações sobre educação em saúde na visão de enfermeiros de saúde da família. Trab. Educ. Saúde, Rio de Janeiro, v. 12 n. 2, p. 253-272,maio/ago. 2014. 
PAIM, J.S.; TEIXEIRA, C.F. - Configuração institucional e gestão do Sistema Único de Saúde: problemas e desafios. Ciênc. saúde coletiva, Rio de Janeiro, v.12, suppl.0, Nov. 2007.

PEREIRA, A.M. - A educação escolarizada deve ensinar o homem a conhecer, fazer, viver juntos e ser. In: IX CONGRESSO NACIONAL DE EDUCAÇÃO - EDUCERE. PUC, Anais... Curitiba PR, p. 5624-5635, 2009.

REIS, D.O., ARAÚJO, E.C., CECÍlIO, L.C.O. Políticas públicas de saúde: Sistema Único de Saúde. Disponível em: 〈www.unasus.unifesp.br>

SAYÃO, Y. Orientação sexual na escola: os territórios possíveis e necessários. In: AQUINO, J. G. (Org.). Sexualidade na escola: alternativas teóricas e práticas. 3. ed. São Paulo, SP: Summus Editorial, 1997.

SANTOS, F.P.A., VIDAL, L.M., BITTENCOURT, I.S., BOERY, R.N.S.O., SENA, E.L.S. Estratégias de enfrentamento dos dilemas bioéticos gerados pela violência na escola. Revista de Saúde Coletiva, Rio de Janeiro, v. 21, n. 1, p. 267-281, 2011.

SESAU. Secretaria de Estado da Saúde de Roraima. Disponível em: www.saude.rr.gov.br

SILVA, L. A. A.; LEITE, M. T.; PINNO, C. Contribuições das comissões de integração ensino-serviço na Educação Permanente em Saúde. Trab. Educ. Saúde, Rio de Janeiro, v. 12 n. 2, p. 403-424,maio/ago. 2014.

SILVA, A. C. S.; SALES, Z. N.; MOREIRA, R. M.; BOERY, E. N.; TEIXEIRA, J. R. B.; BOERY, R. N. D. O. Representações sociais sobre ser saudável de adolescentes escolares. Adolesc.\& Saude, Rio de Janeiro, v. 11, n. 1, p. 24-31, jan/mar 2014.

SOUZA, P. L.; PEREIRA, C. S.; NOGUEIRA, M. L. S.; CUNHA, G. M.; MÖLER, F. O. Projetos PET-Saúde e Educando para a Saúde: Construindo Saberes e Práticas. Revista Brasileira de Educação Médica, 36 (1, Supl. 1), p. 172-177, 2012.

VASCONCELOS, M.; GRILO, M. J. C.; SOARES, S. M. Práticas pedagógicas em atenção primária à saúde: tecnologias para abordagem ao indivíduo, família e comunidade. Belo Horizonte, MG: Nescon/UFMG, Coopmed, 2009. (Caderno de Estudos do Curso de Especialização em Atenção Básica em Saúde da Família). 